\title{
Air pollution and multiple acute respiratory outcomes
}

\author{
Annunziata Faustini ${ }^{1}$, Massimo Stafoggia', Paola Colais ${ }^{1}$, Giovanna Berti², \\ Luigi Bisanti ${ }^{3}$, Ennio Cadum², Achille Cernigliaro ${ }^{4}$, Sandra Mallone ${ }^{5}$, \\ Corrado Scarnato ${ }^{6}$ and Francesco Forastiere ${ }^{1}$ on behalf of the EpiAir \\ Collaborative Group ${ }^{7}$
}

Affiliations: 'Dept of Epidemiology, Regional Health Service, Rome, ${ }^{2}$ Epidemiology Services, Regional Environmental Protection Agency, Turin, ${ }^{3}$ Epidemiology Unit, Local Health Authority, Milan, ${ }^{4}$ Epidemiological Observatory, Regional Health Authority, Palermo, ${ }^{5}$ Centre for Cancer Prevention, Florence, and ${ }^{6}$ Local Health Authority, Bologna, Italy. ${ }^{7}$ A full list of the EpiAir Collaborative Group members and their affiliations can be found in the Acknowledgements section.

Correspondence: A. Faustini, Epidemiology Dept, Regional Health Service of Lazio, V. S. Costanza n 53, 00198 Rome, Italy. E-mail: a.faustinidadeplazio.it

ABSTRACT Short-term effects of air pollutants on respiratory mortality and morbidity have been consistently reported but usually studied separately. To more completely assess air pollution effects, we studied hospitalisations for respiratory diseases together with out-of-hospital respiratory deaths.

A time-stratified case-crossover study was carried out in six Italian cities from 2001 to 2005. Daily particulate matter (particles with a 50\% cut-off aerodynamic diameter of $10 \mu \mathrm{m}$ (PM10)) and nitrogen dioxide $\left(\mathrm{NO}_{2}\right)$ associations with hospitalisations for respiratory diseases $(\mathrm{n}=100690)$, chronic obstructive pulmonary disease (COPD) $(n=38577)$, lower respiratory tract infections (LRTI) among COPD patients $(n=9886)$ and out-of-hospital respiratory deaths $(n=5490)$ were estimated for residents aged $\geqslant 35$ years.

For an increase of $10 \mu \mathrm{g} \cdot \mathrm{m}^{-3}$ in PM10, we found an immediate $0.59 \%$ (lag $0-1$ days) increase in hospitalisations for respiratory diseases and a $0.67 \%$ increase for COPD; the $1.91 \%$ increase in LRTI hospitalisations lasted longer (lag 0-3 days) and the 3.95\% increase in respiratory mortality lasted 6 days. Effects of $\mathrm{NO}_{2}$ were stronger and lasted longer (lag 0-5 days). Age, sex and previous ischaemic heart disease acted as effect modifiers for different outcomes.

Analysing multiple rather than single respiratory events shows stronger air pollution effects. The temporal relationship between the pollutant increases and hospitalisations or mortality for respiratory diseases differs.

@ERSpublications

Analysing multiple rather than single respiratory events shows stronger air pollution effects http://ow.ly/15erE

\footnotetext{
This article has supplementary material available from www.erj.ersjournals.com

Received: Aug 162012 | Accepted after revision: Dec 182012 | First published online: Jan 112013

Support statement: Data collection and analysis of the effects of air pollution on respiratory mortality has been funded by the Italian Ministry of Health, Centro Nazionale per la Prevenzione ed il Controllo delle Malattie, Inquinamento Atmosferico e Salute: Sorveglianza Epidemiologica ed Interventi di Prevenzione, EpiAir. The analysis related to the susceptibility factors for respiratory mortality has been funded by the Italian Ministry of Health, under the Programma Strategico finanziato dal Ministero del Lavoro, della Salute e delle Politiche Sociali, dal titolo ISS: Impatto sanitario associato alla residenza in siti inquinati, in territori interessati da impianti di smaltimenti/incenerimento rifiuti ed alla esposizione ad inquinamento atmosferico in aree urbane. Convenzione n. 41.
}

Conflict of interest: None declared.

Copyright @ERS 2013 


\section{Introduction}

The impact of air pollutants on the respiratory system has been widely and consistently reported in recent years. The short-term effects include decreases in pulmonary function [1], increases in inflammatory markers [2] and respiratory symptoms [3], exacerbations of chronic obstructive pulmonary disease (COPD) and infections [4-9], and increases in respiratory mortality [10-12].

The risk of dying from respiratory diseases associated with particulate matter (PM) (defined either as particles with a $50 \%$ cut-off aerodynamic diameter of $10 \mu \mathrm{m}$ (PM10) or $2.5 \mu \mathrm{m}$ (PM2.5)) is close to $1 \%$ per $10 \mu \mathrm{g} \cdot \mathrm{m}^{-3}$ in several studies worldwide [13], whereas PM effects on hospitalisations or emergency visits for respiratory diseases tend to be higher $(2-3 \%)$ and affect all ages $[4,6-9]$. Nitrogen dioxide $\left(\mathrm{NO}_{2}\right)$ and ozone $\left(\mathrm{O}_{3}\right)$ are associated with even larger increases per $10 \mu \mathrm{g} \cdot \mathrm{m}^{-3}$ (near 3-6\% and 5-6\%, respectively) in asthma exacerbations in children [6, 7, 14-16].

We have recently reported the results of the Italian EpiAir multi-city study (Air Pollution and Health: Epidemiological Surveillance and Primary Prevention) on respiratory mortality that had effects ranging from $2.3 \%$ per $10 \mu \mathrm{g} \cdot \mathrm{m}^{-3} \mathrm{PM} 10$ to $3.5 \%$ per $10 \mu \mathrm{g} \cdot \mathrm{m}^{-3} \mathrm{NO}_{2}[17,18]$. To complete the assessment of PM10 and $\mathrm{NO}_{2}$ effects on respiratory health, we studied emergency hospitalisations for respiratory diseases and for COPD. We also considered out-of-hospital respiratory mortality, since our hypothesis was that the multiple immediate respiratory effects of air pollutants should be considered together to give complete and valid estimates of air pollution effects.

It has already been reported that latency differs with the type of respiratory event. Mortality is a prolonged effect of PM (lasting 4-6 days) [19, 20], while hospitalisations and emergency visits are immediate (lag 01 days and up to 3 days, respectively) [7-9], suggesting that subjects' characteristics and patient management may affect the probability of these different events. The stronger increase in out-of-hospital than in-hospital mortality $[17,21]$ and recent studies on the protective effects of drugs against air pollutant effects $[22,23]$ give support to our hypothesis that various respiratory outcomes have to be analysed together as multiple effects of air pollutants.

\section{Methods \\ Health events}

We considered all emergency hospitalisations of subjects aged $\geqslant 35$ years, who were residents of six Italian cities (Bologna, Florence, Milan, Palermo, Rome and Turin), discharged from a hospital in their city, between January 1, 2001 and December 31, 2005. We selected primary diagnoses of all respiratory diseases (International Classification of Diseases, ninth revision (ICD-9) codes 460-519), COPD (ICD-9 codes 490$492,494,496)$ as primary diagnosis, or secondary diagnosis when respiratory failure (ICD-9 codes 518.5, $518.8,786.0$ ) was the principal diagnosis, and lower respiratory tract infections (LRTI) (ICD-9 codes 466, 480-487) with COPD as secondary diagnosis; we also considered asthma diagnoses (ICD-9 codes 493). Hospitalisations in the following 28 days with the same discharge diagnosis were excluded. Furthermore, we considered all local deaths (ICD-9 codes 460-519) of residents aged $\geqslant 35$ years, in the six cities during 2001-2005. We selected underlying respiratory causes of death reported in the local mortality registries. We defined out-of-hospital deaths as those that occurred at home, in subjects who had not been hospitalised in the previous 2 years, or had been discharged at least 28 days before death.

For each subject, sex, age and previous diseases identified from hospital diagnoses in the preceding 2 years were analysed as potential effect modifiers. The diseases were selected based on the following criteria: 1) diseases related to oxidative stress, systemic inflammation, autonomous nervous system disorders, coagulation disorders and atherosclerosis; 2) heart diseases that may have complicated the natural course of respiratory diseases; and 3) chronic diseases that may generally impair vital functions, such as cancer, chronic hepatic conditions and renal failure.

Data on influenza epidemics were defined, based on National Health Service Sentinel System data, as the 3week period of maximum incidence (generally occurring between January and March) in each city.

\section{Environmental data}

Air pollution data were provided by the Regional Environmental Agencies, which from 2001 to 2005 routinely monitored $\mathrm{PM} 10$ and $\mathrm{NO}_{2}$. A previously-defined algorithm [24] was developed to impute missing values and to calculate daily averages for $\mathrm{PM} 10$ and $\mathrm{NO}_{2}$ in each city. For inclusion, monitored data of daily measures per season had to be at least $75 \%$ complete.

Daily information on temperature, humidity and barometric pressure was provided by the Italian Air Force Meteorological Service (Rome, Italy). Apparent temperature was calculated from air temperature and dewpoint temperature, a proxy of relative humidity [25]. 


\section{Statistical analyses}

A time-series analysis was performed for each city to study the association between air pollutants and health effects. A Poisson regression was applied, controlling for apparent temperature (lag 0-1 days, penalised splines) and low temperature (lag 1-6 days, penalised splines), barometric pressure (lag 0 days, penalised splines), temporary population decreases in the summer and during holidays (a three-level variable taking into account vacation periods spent outside the city and decreased health service availability), and influenza epidemics. Long-term trends and seasonality were controlled for by including a triple interaction of year, month and day of the week in the regression models. Increases in hospitalisations and mortality corresponding to $10 \mu \mathrm{g} \cdot \mathrm{m}^{-3}$ increases in $\mathrm{PM} 10$ or $\mathrm{NO}_{2}$ were estimated and reported as percentages with $95 \%$ confidence intervals. More details about the analysis are reported in previous papers [17, 21] and methods used to analyse hospitalisations have been fully described in a paper about the cardiovascular effects of PM10 [26].

To explore the lag interval of the pollutants' effects, we fitted single-lag models and cubic polynomial distributed lag models $[27,28]$ for each city. 6-day lags were explored from 0 to 5 days preceding hospitalisation or death. Cumulative lags were also analysed for three intervals selected a priori to differentiate immediate (up to lag 1 day), delayed (lag 2-5 days) and prolonged (lag 0-5 days) effects. The cumulative lag interval with the strongest effect and the lowest heterogeneity between cities in the pooled analysis for that lag interval was used in further analysis as the best lag, but lag 0-3 days was preferred to lag 0-5 days for out-of-hospital mortality, in order to better compare the results with those of total respiratory mortality [17].

To estimate the net effect of each pollutant on each respiratory event, the association was evaluated in twopollutant models.

A case-crossover analysis was carried out to investigate the potential modification of the effect of each pollutant on the risk of any respiratory event in each city-specific regression model. A conditional logistic regression was applied, selecting control days with a time-stratified approach (designed to control for season, long-term trend and day of the week) [29], and considering the other covariates as in a Poisson regression approach. Each individual effect modifier was tested by adding to the model an interaction term between each potential effect modifier, one at a time, and the pollutant.

Finally, pooled estimates were obtained from city-specific results by applying a random-effects metaanalysis with maximum likelihood [30]. For each pooled estimate, we estimated the p-values of tests for heterogeneity across cities.

All analyses were carried out using SAS software (Statistical Analysis System, version 8.2; SAS Institute, Inc., Cary, NC, USA) and R software (version 2.8.1; R Foundation for Statistical Computing, Vienna, Austria).

\section{Results}

There were 100690 hospitalisations due to respiratory diseases in the study population from 2001 to 2005 . A total of 38577 (39\%) were due to COPD (24\% of which had a principal diagnosis of respiratory failure) and $9886(10 \%)$ to LRTI in COPD sufferers. There were 5490 out-of-hospital respiratory deaths, accounting for $30.7 \%$ of all respiratory deaths $(n=17862)$. Most hospitalisations for respiratory diseases and COPD, and most out-of-hospital deaths, were observed in Rome, Milan and Palermo, in decreasing order of frequency (table 1). Hospitalisations for LRTI differed slightly; Florence joined Rome and Milan among the cities with the highest values. Respiratory events were more frequent in the cold seasons (October to March), when $56.6 \%$ of hospitalisations and $59.7 \%$ of out-of-hospital deaths occurred (table 1).

There were 185 out-of-hospital deaths related to asthma and 1874 asthma hospitalisations in the six cities over the 5-year period.

Daily mean concentrations of PM10 ranged from $53.9 \mu \mathrm{g} \cdot \mathrm{m}^{-3}$ in Turin to $34.8 \mu \mathrm{g} \cdot \mathrm{m}^{-3}$ in Palermo. $\mathrm{NO}_{2}$ showed greater variability, with the lowest value in Florence $\left(46.1 \mu \mathrm{g} \cdot \mathrm{m}^{-3}\right)$ and the highest in Milan, Turin and Rome $\left(59.2,66.0\right.$ and $62.4 \mu \mathrm{g} \cdot \mathrm{m}^{-3}$, respectively). The apparent temperature showed a clear NorthSouth gradient, with the lowest values in Milan, Turin and Bologna $\left(11.5-13.8^{\circ} \mathrm{C}\right)$ and the highest in Palermo and Rome (15.7-19.4 $\left.{ }^{\circ} \mathrm{C}\right)$. No important differences in humidity or atmospheric pressure were observed between the cities. Complete data on pollutants and meteorological conditions have been reported in previous papers $[17,21,26]$.

The effects of both PM10 and $\mathrm{NO}_{2}$ on hospitalisations for respiratory diseases were immediate (lag 0-1 days), and notable on hospitalisations for COPD, which increased the same day the pollutants increased and decreased immediately after. Hospitalisations for LRTI increased later, on the second day (for PM10) or on the third day (for $\mathrm{NO}_{2}$ ), and reached the strongest values on the fourth day (lag 3 days), suggesting that COPD 
TABLE 1 Multiple respiratory health events in subjects aged $\geqslant 35$ years, by season and city, from 2001 to 2005

Hospitalisations for respiratory diseases

\begin{tabular}{|c|c|c|c|c|}
\hline & & & & \multirow{2}{*}{ deaths } \\
\hline & All respiratory diseases & $\mathrm{COPD}^{\#}$ & LRTI in COPD" & \\
\hline \multicolumn{5}{|l|}{ All seasons } \\
\hline Milan & 19479 (19.3) & $6538(6.5)$ & 1960 (1.9) & 1147 (20.9) \\
\hline Turin & $10100(10.0)$ & $3695(3.7)$ & $1060(1.1)$ & $409(7.4)$ \\
\hline Bologna & $8716(8.7)$ & 3883 (3.9) & $859(0.9)$ & 457 (8.3) \\
\hline Florence & $8725(8.7)$ & $2740(2.7)$ & $1419(1.4)$ & $426(7.8)$ \\
\hline Rome & $37692(37.4)$ & $14713(14.6)$ & $3238(3.2)$ & $2400(43.7)$ \\
\hline Palermo & $15978(15.9)$ & $7008(7.0)$ & $1350(1.3)$ & 651 (11.9) \\
\hline Total & $100690(100.0)$ & 38577 (38.3) & 9886 (9.8) & $5490(100.0)$ \\
\hline \multicolumn{5}{|c|}{ Warm seasons ${ }^{+}$} \\
\hline Milan & $8376(19.2)$ & $2654(6.1)$ & 840 (1.9) & 432 (19.5) \\
\hline Turin & $4168(9.5)$ & 1423 (3.3) & 409 (0.9) & $169(7.6)$ \\
\hline Bologna & $3653(8.4)$ & $1578(3.6)$ & $350(0.8)$ & $187(8.5)$ \\
\hline Florence & $3617(8.3)$ & $1040(2.4)$ & 587 (1.3) & $181(8.2)$ \\
\hline Rome & 16751 (38.3) & $6231(14.3)$ & 1444 (3.3) & $981(44.4)$ \\
\hline Palermo & $7147(16.4)$ & $3039(7.0)$ & $568(1.3)$ & $261(11.8)$ \\
\hline Total & $43712(100.0)$ & 15965 (36.5) & $4198(9.6)$ & $2211(100.0)$ \\
\hline
\end{tabular}

Out-of-hospital respiratory deaths

Data are presented as $\mathrm{n}(\%)$. Chronic obstructive pulmonary disease (COPD) was identified as principal diagnosis of COPD or respiratory failure with COPD as secondary diagnosis; lower respiratory tract infections (LRTI) (bronchitis and pneumonia) were identified as principal diagnosis with COPD as secondary diagnosis. " : percentage of all respiratory diseases; " ${ }^{\natural}$ : deaths of people without hospitalisations in the previous 2 years or with hospitalisation but discharged at least 28 days before death, with estimated percentages of all respiratory deaths; ${ }^{+}$: from April to September.

patients with pulmonary infections are hospitalised later. Finally, out-of-hospital mortality was prolonged (lag 0-5 days), increased steadily until the third day and remained high until the sixth day (fig. 1).

A $10 \mu \mathrm{g} \cdot \mathrm{m}^{-3}$ rise in PM10 gave an increased risk (IR) (95\% CI) of hospitalisations for all respiratory diseases of $0.59 \%(0.10-1.08 \%)$ and for COPD of $0.67 \%(-0.02-1.35 \%)$. Greater increases in risk were observed for LRTI hospitalisations $(1.91 \%(0.06-3.79 \%))$ and for out-of-hospital respiratory mortality $(3.95 \%(1.53-$ $6.43 \%)$ ) (table 2).

A $10 \mu \mathrm{g} \cdot \mathrm{m}^{-3}$ rise in $\mathrm{NO}_{2}$ gave an IR $(95 \% \mathrm{CI})$ of hospitalisations for all respiratory diseases of $1.19 \%(0.23-$ $2.15 \%)$ and for COPD of $1.20 \%(0.17-2.23 \%)$. Greater increases were observed for LRTI (1.79\% (95\% CI $1.16-4.83 \%)$ ) and for out-of-hospital mortality (6.92\% (95\% CI 3.53-10.42\%)) (table 2). The heterogeneity of the effects across cities was very low for both pollutants.

The effect estimates on asthma hospitalisations were estimated only for Rome (the city with the highest frequency). We found the highest values at lag 0-5 days with important but not statistically significant IR (95\% CI) of $6.59 \%(-2.27-16.27 \%)$ for $10 \mu \mathrm{g} \cdot \mathrm{m}^{-3} \mathrm{PM} 10$ and $9.26 \%(-2.66-22.64 \%)$ for $10 \mu \mathrm{g} \cdot \mathrm{m}^{-3} \mathrm{NO}_{2}$ (data not shown). The low number of asthma events did not allow further consideration in the analysis.

To compare the effect sizes between the two pollutants, we estimated the strength of the effects of both pollutants by the interquartile ranges of their concentrations $\left(24.9 \mu \mathrm{g} \cdot \mathrm{m}^{-3}\right.$ and $25.9 \mu \mathrm{g} \cdot \mathrm{m}^{-3}$ for PM10 and $\mathrm{NO}_{2}$, respectively). $\mathrm{NO}_{2}$ had slightly stronger effects than PM10 at the best lag for each pollutant. The effects on respiratory hospitalisations were $1.94 \%$ versus $1.47 \%$ at lag $0-1$ days and $3.10 \%$ versus $1.53 \%$ at lag 0 5 days, respectively. The effects on COPD hospitalisations were $3.13 \%$ versus $1.66 \%$ at lag $0-1$ days; those on LRTI hospitalisations were $4.71 \%$ versus $3.75 \%$, respectively, at lag $0-5$ days; and those on out-ofhospital deaths were $16.26 \%$ versus $11.25 \%$, respectively, at lag 0-5 days. The complete results are reported in the online supplementary table A.

The association between PM10 and hospitalisations was stronger in warm seasons, when compared with cold seasons, for all respiratory events; it was 12 times stronger for respiratory diseases, 7.5 times stronger for COPD and five times stronger for LRTI, indicating that seasons are also an effect modifier (online supplementary table B). Out-of-hospital mortality differed slightly; although it increased 1.7 times in warm seasons, the ratio was much lower than for hospitalisations and no effect modification was statistically supported (online supplementary table $\mathrm{B}$ ). The pattern of associations between $\mathrm{NO}_{2}$ and hospitalisations by season was very similar to what has been seen for PM10.

In the two-pollutant models, when both $\mathrm{PM} 10$ and $\mathrm{NO}_{2}$ were considered, the effects remained but were lower, especially for all respiratory diseases and out-of-hospital mortality, and statistical significance was not 

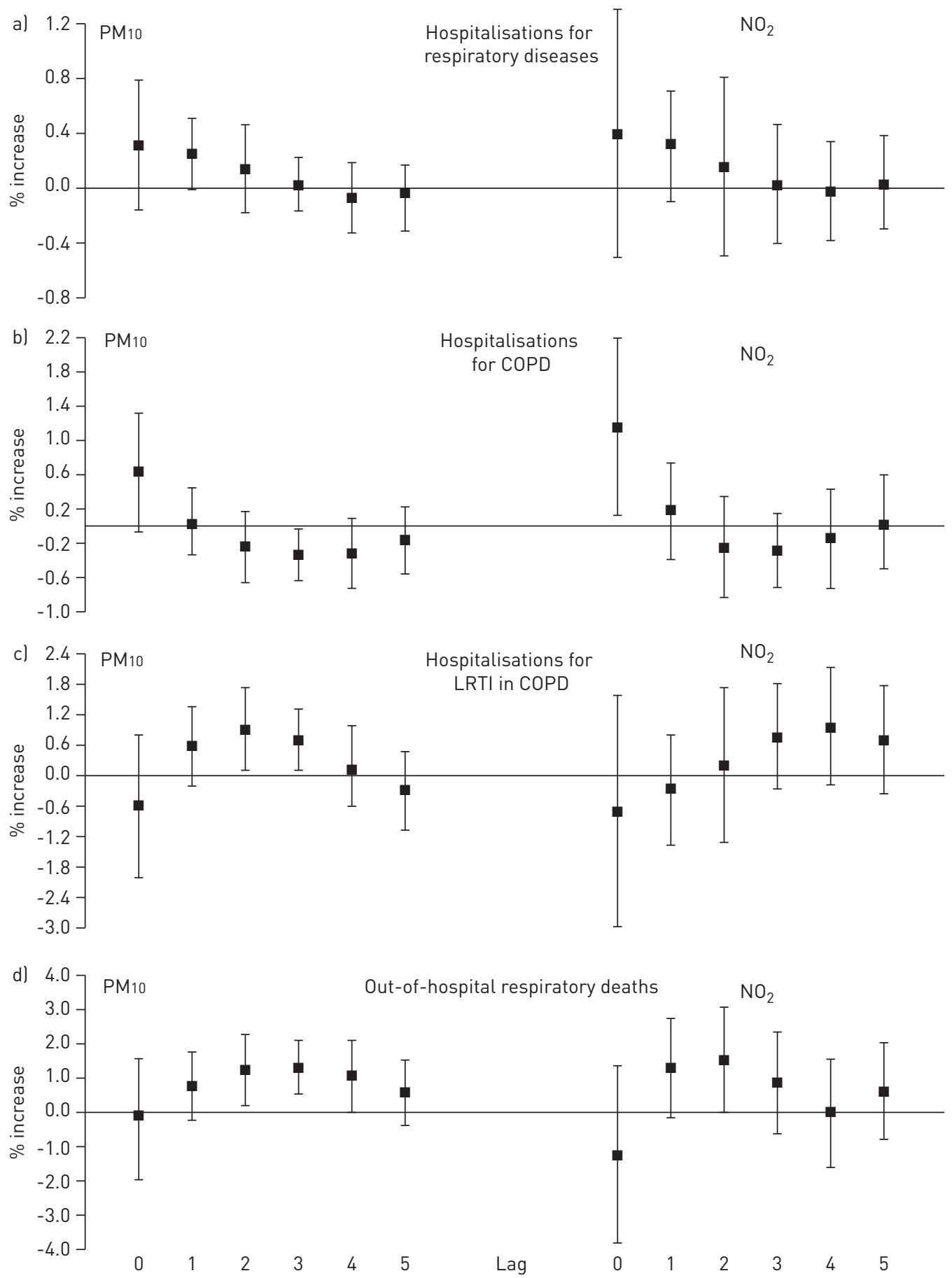

FIGURE 1 Pooled results showing the association between multiple respiratory outcomes and particles with a 50\% cut-off aerodynamic diameter of $10 \mu \mathrm{m}$ (PM10) or nitrogen dioxide $\left(\mathrm{NO}_{2}\right)$, by lag (from constrained distributed lag models), for six cities in 2001-2005. Data are presented as percentage increases of risk of respiratory outcome, and 95\% confidence intervals, relative to a $10 \mu \mathrm{g} \cdot \mathrm{m}^{-3}$ increase in PM10. In distributed lag models, a third-degree polynomial constrain for lags from 0 to 5 days has been applied.

reached (table 3). The correlation between $\mathrm{NO}_{2}$ and $\mathrm{PM} 10$ varied between 0.22 and 0.79 across cities, as a result of different sources and dispersion of the pollutants. This could explain the indeterminate results regarding possible independent effects.

Table 4 (and online supplementary table C) shows the pooled estimates of PM10 effects on respiratory hospitalisations and out-of-hospital mortality, stratified by age group, sex and hospital discharge diagnoses in the previous 2 years. Age was clearly an effect modifier of out-of-hospital mortality, and people were 


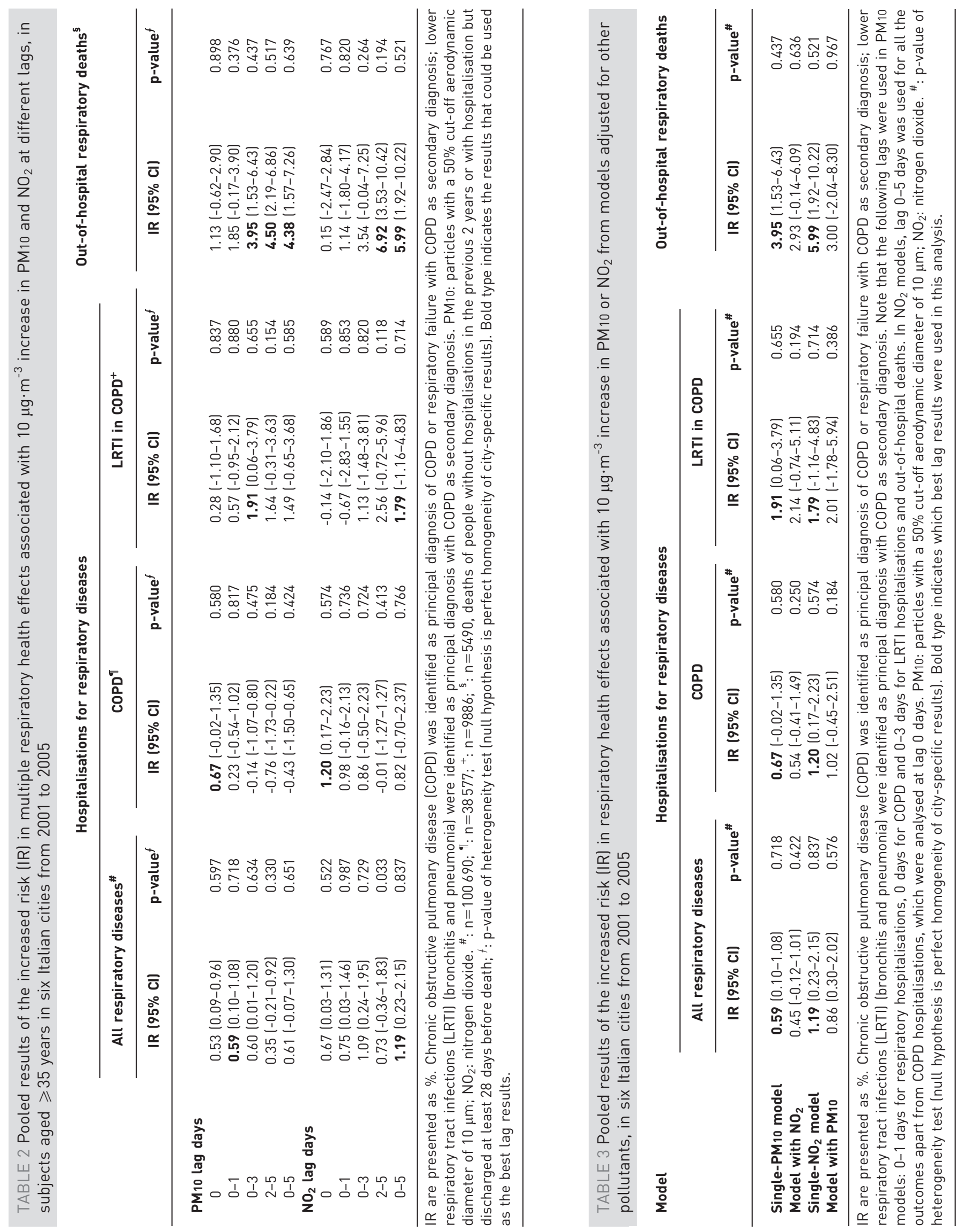


TABLE 4 Pooled results of the increased risk (IR) in multiple respiratory health effects associated with $10 \mu \mathrm{g} \cdot \mathrm{m}^{-3}$ increase in PM10, in subjects aged $\geqslant 35$ years, by demographic characteristics and previous diseases, in six Italian cities from 2001 to 2005

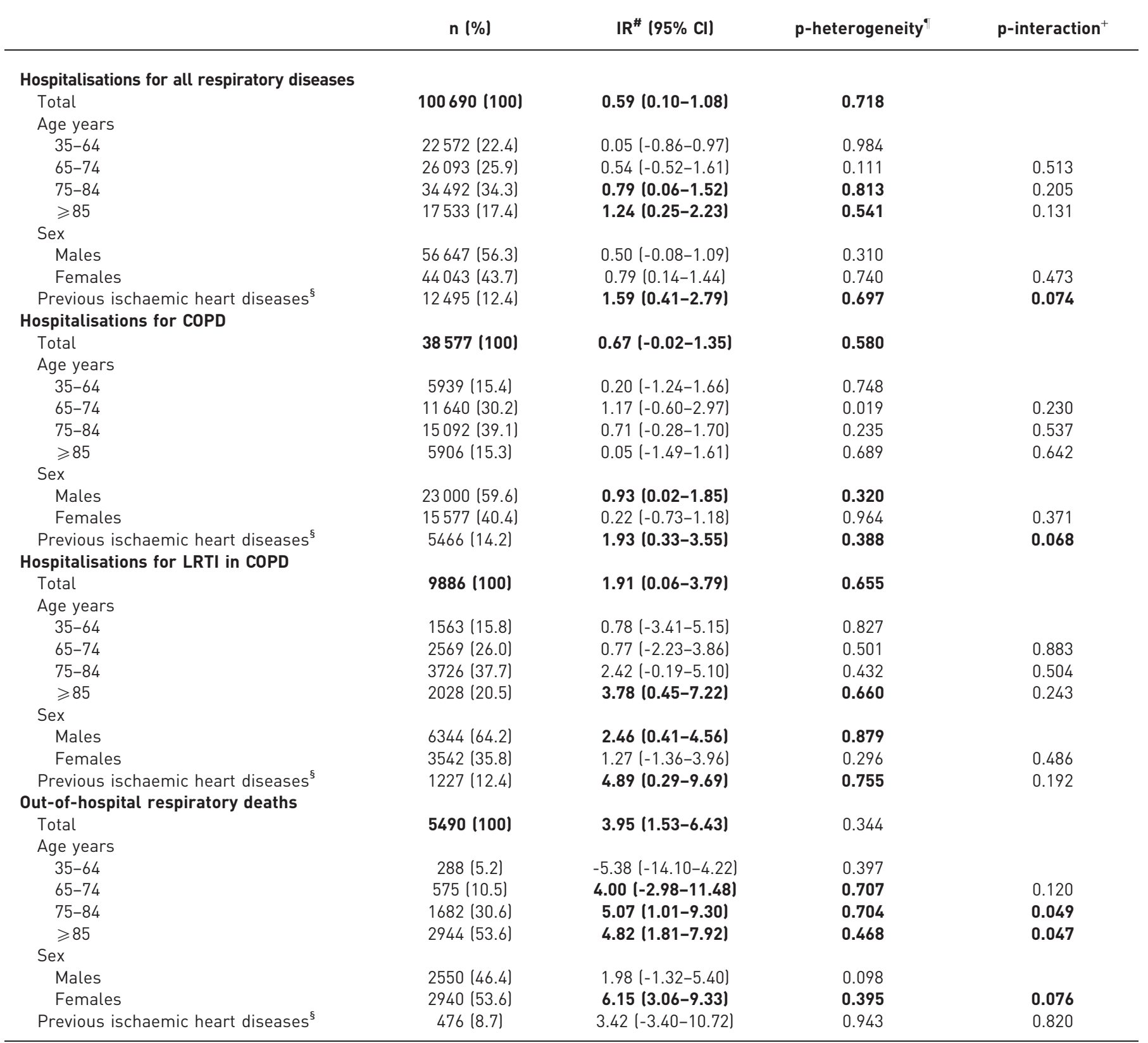

IR are presented as \%. Chronic obstructive pulmonary disease (COPD) was identified as principal diagnosis of COPD or respiratory failure with COPD as secondary diagnosis; lower respiratory tract infections (LRTI) (bronchitis and pneumonia) were identified as principal diagnosis with COPD as secondary diagnosis. PM10: particles with a $50 \%$ cut-off aerodynamic diameter of $10 \mu \mathrm{m}$. ${ }^{\#}$ : risk estimated at the best lag, hospitalisations for all respiratory diseases was lag 0-1 days, for COPD was lag 0 days, for LRTI in COPD was lag 0-3 days, and out-of-hospital mortality was lag 0-3 days; ": $p$-value of heterogeneity test (null hypothesis is perfect homogeneity of city-specific results); ${ }^{+}: p$-value derived from the model with the interaction term (for each condition, the reference category is the group of subjects without the disease); ${ }^{\S}$ : discharge diagnosis in the period 29 days to 2 years before death, for International Classification of Diseases (ninth revision) codes 410-414. Bold type indicates the total effects, the statistically significant results within each variable, and the $p$-interaction values that identify an effect modification.

more likely to die at home if they were older: IR (95\% CI) rose to 5.07\% (1.01-9.30\%) for subjects aged 7584 years and to $4.82 \%(1.81-7.92 \%)$ for those aged $\geqslant 85$ years. Sex was a mild effect modifier, with females $(6.15 \%(3.06-9.33 \%))$ being more likely to die at home than males (1.98\% (-1.32-5.40); p-value for interaction 0.076). In contrast, cancer patients were less likely to die at home (-5.32\% (95\% CI -16.64-7.53); p-value for interaction 0.134 ). 
There was a higher IR $(95 \% \mathrm{CI})$ for subjects aged $\geqslant 85$ years being hospitalised for all respiratory disease of $1.24 \%(0.25-2.23 \%)$, compared with younger subjects, but the difference was not statistically significant. In contrast, a previous diagnosis of ischaemic heart disease gave an increased risk of hospitalisation, suggesting a possible effect modification on all respiratory diseases, with IR (95\% CI) of $1.59 \%(0.41-2.79 \%)$, on COPD exacerbation $(1.93 \%(0.33-3.55 \%))$, and on LRTI in COPD sufferers (4.89\% (0.29-9.69\%)). Among non-cardiac diseases, only chronic liver disease possibly increased the likelihood of a hospitalisation for LRTI. We did not find any evidence of modification of the effects of air pollution on respiratory diseases for diseases of pulmonary circulation (ICD-9: 415-417), conduction disorders (ICD-9: 426), arrhythmias (ICD-9: 427), heart failure (ICD-9: 428) and, among non-cardiac diseases, for cancer (ICD-9: 140-208), diabetes (ICD-9: 250), cerebrovascular diseases (ICD-9: 430-438), chronic pulmonary diseases (ICD-9: 490-505) or renal failure (ICD-9: 584-588).

\section{Discussion}

We found an immediate increase in emergency hospitalisations for respiratory diseases associated with $\mathrm{PM} 10$, and even more strongly associated with $\mathrm{NO}_{2}$. The largest and longest lasting effect was observed on hospitalisations due to LRTI in COPD sufferers. All effects on hospitalisations were stronger in warm seasons compared with cold seasons. Subjects with a previously diagnosed ischaemic heart disease showed the strongest effects of PM10. The risk of dying out of hospital was much higher than that of being hospitalised; it did not decrease over the cumulative 6-day exposure and did not show seasonal differences.

The immediate effect on hospitalisations for respiratory diseases confirms most results from previous studies on adults [5,8]. Longer cumulative lags have been consistently reported for respiratory hospitalisations in children $[14,15]$. The greatest effect has been observed on hospitalisations due to LRTI in COPD sufferers; it lasted longer, up to 4 or 6 days for different pollutants, and it was consistent across cities. Since we studied only pneumonia in COPD, we concluded that worsening COPD causes immediate recourse to hospitalisation, while pulmonary infections in COPD patients took more time to become serious, resulting in more time elapsed before hospitalisation for COPD patients who developed pulmonary infections. Important increases in hospitalisations for LRTI associated with rises in $\mathrm{PM} 10$ or $\mathrm{NO}_{2}$ were reported both in adults [31,32] and in children [33]. Also, hospitalisations for chronic respiratory diseases (COPD) associated with rising PM10 showed higher increases than those for all respiratory diseases, as has already been reported [34]. Clearly, COPD patients are very likely to be susceptible to the short-term effects of air pollutants [9, 31, 35-37].

A slightly stronger effect of $\mathrm{NO}_{2}$ than PM10 on respiratory hospitalisations has been reported in some previous studies of both pollutants $[6,14]$, but the difference was small or not appreciable. However, the literature shows that $\mathrm{NO}_{2}$ had a stronger effect than PM10 on child morbidity and on adult mortality, and in our study the $\mathrm{NO}_{2}$ effects on hospitalisation for respiratory diseases and for COPD were almost twice as large as those due to PM10. While this supports the conclusion that $\mathrm{NO}_{2}$ has a greater effect on respiratory health, the variability of the correlation between the two pollutants prevents us from drawing a clear conclusion regarding their independent effects.

The warm season exacerbates the effects of pollutants, especially those related to $\mathrm{NO}_{2}$, although a complete explanation for this can still not be found in the literature.

The elderly and those with previous ischaemic disease were more likely to be hospitalised following PM increases, but no effect modification was appreciated. The same effect has been previously reported for other cardiac diseases [22] and the most elderly subjects [38]. It is noteworthy that we did not find any modification with age of the risk of hospitalisations due to specific respiratory diseases (COPD and LRTI), which are likely to be influenced by other factors.

The high estimates of out-of-hospital mortality we found here for $\mathrm{PM} 10$, and even more for $\mathrm{NO}_{2}$, were consistent with the results we found for total respiratory mortality [17, 18], and confirm the stronger effect of $\mathrm{NO}_{2}$ than PM reported in other studies $[19,39]$. However, the higher increases in mortality than in hospitalisations, which we found for both pollutants, contrast with the results of most previous studies that reported higher risks of respiratory hospitalisations than of respiratory mortality [7-9, 13]. Although not excluding the possibility that different habits of recourse to hospitals may explain this disagreement, the more likely explanation is, in our opinion, the shorter lag time (0-1 days) used in most studies in contrast to the prolonged lag ( $0-5$ days) we used here and in previous studies analysing total respiratory mortality $[17,18]$. Shorter lag times have usually been considered more suited for natural mortality; however, previous studies that used a lag of 0-6 days [19, 20,39] found higher estimates of respiratory mortality associated with both $\mathrm{PM}$ and $\mathrm{NO}_{2}$. Conversely, it has been demonstrated that the effect of air pollution on mortality spreads over 2 days [27]. 
Having no previous hospitalisations has previously been recognised as increasing mortality risk [17-19], since it assumes hospitalisation functions as a temporary protective factor against air pollution and death, because it reduces exposure and provides effective treatment for chronic diseases. This is the first time that the factors linked to dying out of hospital were specifically analysed, and the results would suggest that very old people are hospitalised less frequently, while the risk of dying related to air pollution does not seem to be influenced by the presence of chronic diseases.

This study takes a new approach to assess the health effects of air pollution by analysing hospitalisations and out-of-hospital mortality simultaneously as multiple effects. Not having been able to include emergency visits among the respiratory effects of air pollution is clearly a limit of our analysis, given their importance in assessing air pollutant effects $[7,16,40]$. However, this approach allowed us to obtain a more complete picture of air pollution effects and to detect conditions of susceptibility for different outcomes.

Several conclusions can be drawn from the present study. 1) $\mathrm{PM} 10$ and $\mathrm{NO}_{2}$ increased hospitalisations and mortality for respiratory diseases. 2) Subjects with previous cardiac ischaemic diseases were affected more strongly by PM10 than their healthier counterparts. 3) Air pollution effects on hospitalisation in Italy are stronger during the warm period of the year, confirming what has been already observed for mortality. 4) A more complete picture of the short-term respiratory effects of air pollutants is obtained when both hospitalisations and out-of-hospital deaths are examined. Air pollution suddenly aggravates COPD, leading to immediate hospitalisation, and/or promotes respiratory infections that slowly lead to hospitalisation or to death at home.

\section{Acknowledgements}

The members of the EpiAir Collaborative Group and their affiliations are as follows. Milan, Italy: L. Bisanti, G. Randi and M. Rognoni (all Epidemiology Unit, Local Health Authority, Milan). Mestre-Venice, Italy: L. Simonato and R. Tessari (both Environmental and Public Health Dept, University of Padua, Padua, Italy). Turin, Italy: G. Berti, E. Cadum, M. Chiusolo, M. Grosa, C. Ivaldi, R. Pelosini and S. Poncino (all Regional Environmental Protection Agency of Piedmont, Turin), and C. Galassi (Giovanni Battista Hospital and Centre for Cancer Prevention, Turin). Bologna, Italy: N. Caranci, G. Pace, B. Pacelli, P. Pandolfi and C. Scarnato (all Epidemiology Unit, Local Health Authority, Bologna, Italy), R. Miglio (Statistical Dept, University of Bologna, Bologna), and G. Zanini (Italian National Agency for New Technologies, Energy and Sustainable Economic Development, Bologna). Florence, Italy: G. Accetta, E. Chellini and S. Mallone (all Institute for Cancer Study and Prevention, Florence), M. Baccini and A. Biggeri (both Dept of Medical Statistics, University of Florence, Florence), A. Barchielli (Epidemiology Dept, Local Health Authority, Florence), D. Grechi (Regional Environmental Protection Agency of Tuscany, Florence) and D. Nuvolone (epidemiology observer; Regional Health Agency of Tuscany, Florence). Pisa, Italy: S. Baldacci and G. Viegi (both Epidemiology Unit, National Research Council of Italy, Pisa), and M.A. Vigotti (Biology Dept, University of Pisa, Pisa). Rome, Italy: P. Colais, A. Faustini, F. Forastiere and M. Stafoggia (all Epidemiology Dept, Regional Health Service of Lazio, Rome). Taranto, Italy: S. Minerba (Epidemiology Dept, Local Health Authority, Taranto) and M. Serinelli (Regional Environmental Protection Agency of Puglia, Bari, Italy). Cagliari, Italy: P. Dessi (Local Health Authority, Cagliari). Palermo, Italy: A. Cernigliaro and S. Scondotto (both epidemiology observers; Regional Health Agency of Sicily, Palermo).

The authors thank Margaret Becker (freelance medical editor; Rome) for revising the English, and Simona Ricci (Dept of Epidemiology, Regional Health System of Lazio, Rome) for her help with the figure.

\section{References}

1 Lagorio S, Forastiere F, Pistelli R, et al. Air pollution and lung function among susceptible adult subjects: a panel study. Environ Health 2006; 5: 11.

2 Zeka A, Zanobetti A, Schwartz J. Individual-level modifiers of the effects of particulate matter on daily mortality. Am J Epidemiol 2006; 163: 849-859.

3 Delfino RJ, Gong H Jr, Linn WS, et al. Asthma symptoms in Hispanic children and daily ambient exposures to toxic and criteria air pollutants. Environ Health Perspect 2003; 111: 647-656.

Schwartz J. Air pollution and hospital admissions for respiratory disease. Epidemiology 1996; 7: 20-28.

Atkinson RW, Anderson HR, Sunyer J, et al. Acute effects of particulate air pollution on respiratory admissions. Results from APHEA 2 Project. Am J Respir Crit Care Med 2001; 164: 1860-1866.

6 Barnett AG, Williams GM, Schwartz J, et al. Air pollution and child respiratory health: a case-crossover study in Australia and New Zealand. Am J Respir Crit Care Med 2005; 171: 1272-1278.

$7 \quad$ Peel J, Tolbert PE, Klein M, et al. Ambient air pollution and respiratory emergency department visits. Epidemiology 2005; 16: 164-174.

8 Medina-Ramòn M, Zanobetti A, Schwartz J. The effect of ozone and PM10 on hospital admissions for pneumonia and chronic obstructive pulmonary disease: a national multicity study. Am J Epidemiol 2006; 163: 579-586.

9 Dominici F, Peng RD, Bell ML, et al. Fine particulate air pollution and hospital admission for cardiovascular and respiratory diseases. JAMA 2006; 295: 1127-1134.

10 Dominici F, McDermott A, Daniels M, et al. Revised analyses of the National Morbidity, Mortality, and Air Pollution Study: mortality among residents of 90 cities. J Toxicol Environ Health A 2005; 68: 1071-1092.

11 Katsouyanni K, Touloumi G, Samoli E, et al. Confounding and effect modification in the short-term effects of ambient particles on total mortality: results from 29 European cities within the APHEA2 Project. Epidemiology 2001; 12: 521-531.

12 Ostro B, Feng WY, Broadwin R, et al. The effects of components of fine particulate air pollution on mortality in California: results from CALFINE. Environ Health Perspect 2007; 114: 13-19. 
13 Pope CA 3rd, Dockery DW. Health effects of fine particulate air pollution: lines that connect. J Air Waste Manag Assoc 2006; 56: 709-742.

14 Galán I, Tobías A, Banegas JR, et al. Short-term effects of air pollution on daily asthma emergency room admissions. Eur Respir J 2003; 22: 802-808.

15 Babin SM, Burkom HS, Holtry RS, et al. Pediatric patient asthma-related emergency department visits and admissions in Washington, DC, from 2001-2004, and associations with air quality, socio-economic status and age group. Environ Health 2007; 6: 9.

16 Strickland MJ, Darrow LA, Klein M, et al. Short-term associations between ambient air pollutants and pediatric asthma emergency department visits. Am J Respir Crit Care Med 2010; 182: 307-316.

17 Faustini A, Stafoggia M, Berti G, et al. The relationship between ambient particulate matter and respiratory mortality: a multi-city study in Italy. Eur Respir J 2011; 38: 538-547.

18 Chiusolo M, Cadum E, Stafoggia M, et al. Short-term effects of nitrogen dioxide on mortality and susceptibility factors in 10 Italian cities: the EpiAir study. Environ Health Perspect 2011; 119: 1233-1238.

19 Hoek G, Brünekreef B. Daily mortality and air pollution in the Netherlands. J Air Waste Manage Assoc 2000; 50: 1380-1389.

20 Analitis A, Katsouyanni K, Dimakopoulou K, et al. Short-term effects of ambient particles on cardiovascular and respiratory mortality. Epidemiology 2006; 17: 230-233.

21 Stafoggia M, Forastiere F, Faustini A, et al. Susceptibility factors to ozone-related mortality: a population-based case-crossover analysis. Am J Respir Crit Care Med 2010; 182: 376-384.

22 Barclay JL, Miller BG, Dick S, et al. A panel study of air pollution in subjects with heart failure: negative results in treated patients. Occup Environ Med 2009; 66: 325-334.

23 Qian Z, Lin HM, Chinchilli VM, et al. Associations between air pollution and peak expiratory flow among patients with persistent asthma. J Toxicol Environ Health A 2009; 72: 39-46.

24 Biggeri A, Bellini P, Terracini B. Metanalisi italiana degli studi sugli effetti a breve termine dell'inquinamento atmosferico - MISA 1996-2002 [Meta-analysis of the Italian studies on short-term effects of air pollution - MISA 1996-2002]. Epidemiol Prev 2004; 28: 4-100.

25 Steadman RG. The assessment of sultriness. Part I: a temperature-humidity index based on human physiology and clothing science. J Appl Meteor 1979; 18: 861-873.

26 Colais P, Faustini A, Stafoggia M, et al. Particulate air pollution and hospital admissions for cardiac diseases in potentially sensitive subgroups. Epidemiology 2012; 23: 473-481.

27 Schwartz J. The distributed lag between air pollution and daily deaths. Epidemiology 2000; 11: 320-326.

28 Zanobetti A, Wand MP, Schwartz J, et al. Generalized additive distributed lag models: quantifying mortality displacement. Biostatistics 2000; 1: 279-292.

29 Levy D, Lumley T, Sheppard L, et al. Referent selection in case-crossover analyses of acute health effects of air pollution. Epidemiology 2001; 12: 186-192.

30 Normand SL. Meta-analysis: formulating, evaluating, combining and reporting. Stat Med 1999; 18: 321-359.

31 Zanobetti A, Schwartz J, Gold D. Are there sensitive subgroups for the effects of airborne particles? Environ Health Perspect 2000; 108: 841-845.

32 Zanobetti A, Schwartz J. Air pollution and emergency admissions in Boston, MA. J Epidemiol Community Health 2006; 60: 890-895.

33 Lin M, Stieb DM, Chen Y. Coarse particulate matter and hospitalization for respiratory infections in children younger than 15 years in Toronto: a case-crossover analysis. Pediatrics 2005; 116: e235-e240.

34 Belleudi V, Faustini A, Stafoggia M, et al. Impact of fine and ultrafine particles on emergency hospital admissions for cardiac and respiratory diseases. Epidemiology 2010; 21: 414-423.

35 Sunyer J, Schwartz J, Tobias A, et al. Patients with chronic obstructive pulmonary disease are at increased risk of death associated with urban particle air pollution: a case-crossover analysis. Am J Epidemiol 2000; 151: 50-56.

36 Bateson TF, Schwartz J. Who is sensitive to the effects of particulate air pollution on mortality? A case-crossover analysis of effect modifiers. Epidemiology 2004; 15: 143-149.

37 Faustini A, Stafoggia M, Cappai G, et al. Short-term effects of air pollution in a cohort of patients with chronic obstructive pulmonary disease. Epidemiology 2012; 23: 861-879.

38 Halonen JI, Lanki T, Yli-Tuomi T, et al. Urban air pollution, and asthma and COPD hospital emergency room visits. Thorax 2008; 63: 635-641.

39 Fischer P, Hoek G, Brunekreef B, et al. Air pollution and mortality in the Netherlands: are the elderly more at risk? Eur Respir J 2003; 21: Suppl. 40, 34s-38s.

40 Stieb DM, Szyszkowicz M, Rowe BH, et al. Air pollution and emergency department visits for cardiac and respiratory conditions: a multi-city time-series analysis. Environ Health 2009; 8: 25. 